\title{
Oxygen isotope analysis of levoglucosan, a tracer of wood burning, in experimental and ambient aerosol samples
}

Blees, J. ${ }^{1}$, Saurer, M. ${ }^{1,2}$, Siegwolf, R.T.W. ${ }^{1,}{ }^{2}$, Ulevicius, V. ${ }^{3}$, Prevôt, A.S.H. ${ }^{2}$, Dommen, J. ${ }^{2}$, Lehmann, M.M. ${ }^{1,2, *}$

${ }^{1}$ Laboratory of Atmospheric Chemistry, Paul Scherrer Institute (PSI), Villigen, Switzerland

${ }^{2}$ Forest Dynamics, Swiss Federal Institute for Forest, Snow, and Landscape Research (WSL), Birmensdorf, Switzerland

${ }^{3}$ Department of Environmental Research, SRI Center for Physical Sciences and Technology, Vilnius, Lithuania

$\begin{array}{ll}\text { *Corresponding Author: } & \text { Marco M. Lehmann } \\ \text { Email: } & \text { marco.lehmann@alumni.ethz.ch }\end{array}$

This document is the accepted manuscript version of the following article:

Blees, J., Saurer, M., Siegwolf, R. T. W., Ulevicius, V., Prevôt, A. S. H., Dommen, J., \& Lehmann, M. M. (2017). Oxygen isotope analysis of levoglucosan, a tracer of wood burning, in experimental and ambient aerosol samples. Rapid Communications in Mass spectrometry, 31(24), 2101-2108. https://doi.org/10.1002/rcm.8005 


\begin{abstract}
Rationale Levoglucosan is formed from cellulose during biomass burning. It is therefore often used as a specific tracer to quantify the contribution of wood burning to the aerosol loading. The stable oxygen isotope composition $\left(\delta^{18} \mathrm{O}\right)$ of biomass is determined by the water cycle and varies regionally, and hence the $\delta^{18} \mathrm{O}$ value of levoglucosan could help to identify source regions of organic aerosols.
\end{abstract}

Methods After solvent extraction of the organic fraction and concentration steps, a recently developed methylation derivatisation technique was applied on experimental (i.e. controlled wood burning experiments) and on ambient aerosol samples from Switzerland and Lithuania. The method achieves sufficient compound separation for isotope analysis in atmospheric particulate matter, enabling $\delta^{18} \mathrm{O}$ analysis of levoglucosan by gas chromatography/pyrolysis - isotope ratio mass spectrometry (GC/Pyr-IRMS), with a precision better than $1.0 \%$ and an accuracy of $0.3 \%$.

Results The levoglucosan $\delta^{18} \mathrm{O}$ released during controlled wood burning experiments was not significantly different from the cellulose $\delta^{18} \mathrm{O}$, which implies very little or no isotope fractionation during wood burning under the given conditions. While $\delta^{18} \mathrm{O}$ values of levoglucosan in Swiss samples were as expected for the source region, those in Lithuania were 1 - 4 \%o lower than expected. This may be due to differences in vegetation (grass vs. wood) or burning conditions (high vs. low temperatures).

Conclusions Low oxygen isotope fractionation between cellulose and levoglucosan and clear differences in levoglucosan $\delta^{18} \mathrm{O}$ values between the Swiss and Lithuanian ambient samples demonstrate that our new method is useful for source appointment studies on wood-burning derived aerosols.

Keywords: anhydrosugar, emission, fire, smoke, tree, water vapour 


\section{Introduction}

Atmospheric particulate matter (PM) is relevant in both climate change and respiratory health problems ${ }^{[1]}$. Its composition is often complex, with many structurally different compounds making up minor fractions of the bulk. The organic aerosol fraction, comprising a major part of atmospheric $\mathrm{PM}^{[2]}$, consists of a large number of different compounds. The chemical identity of those compounds can be indicative of sources. Therefore, a number of studies have resorted to compound-specific analyses to address the sources of atmospheric PM ${ }^{[3,4]}$. Some of those compounds are derived from biomass burning of wood and crop residues, creating high concentrations of organic aerosols that can be transported over long distances, potentially crossing national borders and causing health problems elsewhere. However, reliable tracers for detecting long-range transport of particles from biomass burning are currently still lacking.

Numerous studies in a wide range of scientific fields have shown that stable isotope ratios of carbon and oxygen in biologically-derived marker molecules (biomarkers) are a versatile tool to investigate biochemical pathways and origin of the biomarker in question ${ }^{[5-7]}$. The stable isotope ratio of organic compounds depends on the isotope composition of the source, environmental conditions and specific (bio)chemical pathways and mechanisms that lead to the formation of the compound. The stable isotope composition of a compound that was sampled from soils or collected as aerosols after biomass burning can therefore be used to identify a source.

Carbon isotopes have so far been applied successfully in studies on organic aerosols ${ }^{[5,8-13]}$, in particular on levoglucosan in source apportionment studies ${ }^{[4,11]}$. Levoglucosan and other anhydrosugars can be highly abundant in PM samples and function as specific tracers for biomass/wood burning, or more specifically for the thermal decomposition of cellulose ${ }^{[14,15]}$. Sang et al. ${ }^{[11]}$, showed that levoglucosan from wood burning is slightly isotopically enriched in ${ }^{13} \mathrm{C}$ compared to the parent material $\left(\delta^{13} C_{\text {holocellulose }}-\delta^{13} C_{\text {levoglucosan }}=-1.89 \%\right)$. This is in line with studies showing that the water soluble organic carbon fraction originating from wood burning in Zürich, Switzerland, was found to be enriched in ${ }^{13} \mathrm{C}$ relative to other organic fractions ${ }^{[16]}$. The C- 
isotopic difference between sources is in a range of a few per mil and in principle an isotopic separation of this magnitude can be enough to distinguish between aerosol sources. However, the information that can be extracted from carbon stable isotope measurements is mainly limited to biochemical differences in carbon fixation (e.g., C3, C4, CAM plants) and to environmental impacts on plant physiology (e.g., weather, drought stress), while information on actual geographical location is restricted ${ }^{[17]}$.

Alternatively, the large degree of oxygenation of many organic aerosols, such as levoglucosan, makes ${ }^{18} \mathrm{O}$ an attractive candidate for additional isotopic studies on aerosols. The oxygen isotopes in biomass record a signal of the hydrological cycle ${ }^{[18-20]}$, providing information independent from the carbon cycle. The oxygen isotopic composition of water in the atmosphere is strongly influenced by the condensation temperature in clouds ${ }^{[18]}$ (the lower the temperature, the less $\mathrm{H}_{2}{ }^{18} \mathrm{O}$ in the water), and by the continental effect, i.e. the distance over which the moisture is transported away from the oceans into the continents (the more continental, the less $\mathrm{H}_{2}{ }^{18} \mathrm{O}$ in the water). The same mechanisms can be observed for air masses that are transported into high elevations of the mountains. This causes strong spatial $\delta^{18} \mathrm{O}$ variability for precipitation water. Through studies on precipitation, soil water, and tree rings, the source $\delta^{18} \mathrm{O}$ values for various regions are well known ${ }^{[21-23]}$. The source water is taken up by plants where it experiences an ${ }^{18} \mathrm{O}$-enrichment in leaf tissues due to transpiration ${ }^{[19,20]}$. The magnitude of the leaf water enrichment depends mainly on atmospheric humidity, temperature, and plant physiological responses ${ }^{[24]}$. The oxygen isotopic signal of leaf water equilibrates with atmospheric $\mathrm{CO}_{2}{ }^{[25]}$, that is taken up and incorporated into plant organic matter during photosynthesis. Due to a rapid exchange of the oxygen in a carbonyl group of carbohydrates with the oxygen in the surrounding water ${ }^{[26,27]}$, a process that is known as the biosynthetic fractionation factor $\left(\varepsilon_{0}\right)$, plant compounds such as cellulose are on average $27 \%$ enriched in ${ }^{18} \mathrm{O}$ compared to leaf water ${ }^{[22,28,29]}$. Modelling studies that successfully reproduced regional patterns confirm that potential source $\delta^{18} \mathrm{O}$ values can be predicted accurately from treering cellulose ${ }^{[30-32]}$. Thus far, studies on oxygen isotopes in atmospheric sciences have mainly 
focused on CO, sulfates and phosphates ${ }^{[6,33,34]}$. As far as we know, no study has yet reported compound-specific oxygen isotope ratios in organic aerosols. However, in order to use aerosol $\delta^{18} \mathrm{O}$ data effectively, first a reproducible analytical method needs to be developed and second both the source and the aerosol $\delta^{18} \mathrm{O}$ signal must be known to determine potential isotope fractionation during the emission process (i.e. wood/biomass burning). A better understanding of these isotope fractionation processes could significantly increase the explanatory power of isotope-based source apportionment studies. For instance, a multi-isotope approach with carbon and oxygen isotopes could facilitate the identification of the aerosol origin and the source of the burned biomass ${ }^{[35-37]}$.

In this study (1) we established a new protocol for $\delta^{18} \mathrm{O}$ measurement of levoglucosan, taking advantage of a recently published methylation derivatisation method for carbohydrates ${ }^{[38]}$, which was already successfully applied on leaf carbohydrates ${ }^{[27,39]}$; (2) we investigated isotope fractionation processes modulating $\delta^{18} \mathrm{O}$ values of levoglucosan in a controlled wood burning experiment using beech and pine wood; (3) we determined oxygen isotope exchange between levoglucosan and ${ }^{18} \mathrm{O}$-labelled water vapour and (4) $\delta^{18} \mathrm{O}$ values of levoglucosan in ambient aerosol samples from Switzerland and Lithuania. To our knowledge this is the first dataset of compoundspecific $\delta^{18} \mathrm{O}$ values of levoglucosan in experimental and ambient samples.

\section{Methods}

\section{Experimental setup}

Controlled wood burning experiments:

Two types of wood with distinct different properties from two locations in Switzerland (Pine soft wood from the south side of the Alps, canton of Wallis, 2 experiments, and beech hard wood from the canton of Aargau, north of the Alps, 2 experiments) were burned in a cast-iron log-wood stove (Type Avant, 2009, Attika, Cham, Switzerland) ${ }^{[40]}$. Pine wood from Wallis was all taken from one tree from the Pfynwald area $\left(46.30^{\circ} \mathrm{N}, 7.59^{\circ} \mathrm{E}\right)$, a valley with $550 \mathrm{~mm}$ precipitation per year and a mean annual temperature of $10.1^{\circ} \mathrm{C}$. Temperatures on the valley floor in this area often exceed 30 
${ }^{\circ} \mathrm{C}$ in summer. Beech wood from Aargau was obtained from one batch of fire wood of uniform age structure. Yearly precipitation in the canton Aargau is around twice as high as in the Pfynwald, with a mean annual temperature of $9.4{ }^{\circ} \mathrm{C}$. Prior to the experiments the wood was left to dry under a roof in a ventilated space outside.

Controlled wood burning experiments were performed on dry and sunny days with low relative humidity (RH $~ 50 \%$ ). Air supply during burning was kept similar by keeping the air inflow lever of the oven in the open position, ensuring maximum supply of oxygen. When wood burning wpas at maximum intensity, the exhaust was collected through a nozzle directly above a $3 \mathrm{~m}$ high chimney. Although wind speeds during the experiments were low, we observed some dispersion of the chimney exhaust, which potentially caused mixing of aerosol samples with ambient air. However, the nozzle was near the exhaust during the entire sampling time. Air collected by the nozzle was drawn through stainless steel tubing at a rate of $50 \mathrm{~L} \mathrm{~min}^{-1}$ through quartz fibre filters $(90 \mathrm{~mm}$ diameter) previously baked for 24 hours at $450{ }^{\circ} \mathrm{C}$. Filters were subsequently packed in pre-baked aluminium foil and stored at $-20{ }^{\circ} \mathrm{C}$ until extraction. Filters were dry after the sampling period, i.e. no condensation water was collected on the filters.

Oxygen isotope exchange experiment:

Several samples of $0.5 \mathrm{mg}$ levoglucosan standard material in open silver capsules were placed in a 1-L desiccator for $72 \mathrm{~h}$. The atmospheric humidity in the closed desiccator was fully saturated with ${ }^{18} \mathrm{O}$-depleted water $\left(\delta^{18} \mathrm{O}=-367.4 \%\right.$ ). All capsules were freeze-dried for $24 \mathrm{~h}$, folded, and $\delta^{18} \mathrm{O}$ values determined as described below for bulk samples.

Ambient samples:

Environmental samples from two locations in Europe were used for comparison. An alpine site in the south of Switzerland in the Magadino plain, close to the Lago Maggiore, $\left(46.16^{\circ} \mathrm{N}, 8.93^{\circ} \mathrm{E}\right.$, $203 \mathrm{~m}$ a.s.1.) and about two kilometres outside of Cadenazzo, was chosen as a comparison site for 
wood burning, since wood burning is a major source of heating in this area in winter ${ }^{[41,42]}$. Five samples that were collected on quartz fibre filters between 25 January and 12 March 2011 were used. Based on the location close to wood burning in the valley, photochemical ageing is not expected to have a significant influence on these samples.

The second sampling site was located in Lithuania, at the coastal Preila environmental pollution research station $\left(55.92^{\circ} \mathrm{N}, 21.00^{\circ} \mathrm{E}\right)^{[43,44]}$. Two samples from March 2014 were collected on quartz fibre filters and chosen based on high particulate matter (PM10) loading events. These events have been linked to grass burning episodes in the Kaliningrad region (Russia), Belarus and the Ukraine [44].

\section{Bulk wood and cellulose extraction and analysis}

Wood samples were taken throughout the logs and homogenised using a ball mill (Mixer Mill MM200, Retsch, Haan, Germany). An aliquot of the milled and homogenised wood samples was transferred into teflon filter bags (Ankom Technology, Macedon, NY, USA) for cellulose extraction

${ }^{[45]}$. Briefly, lignin was removed in an ultrasonic bath for $24 \mathrm{~h}$ at $70{ }^{\circ} \mathrm{C}$ using a 2-L distilled water solution consisting of $24 \mathrm{~g} \mathrm{NaClO}_{2}$ and $8 \mathrm{~mL}$ acetic acid. The solution was renewed every $3 \mathrm{~h}$ and replaced by a 2-L solution with $72 \mathrm{~g} \mathrm{NaClO}_{2}$ and $8 \mathrm{~mL}$ acetic acid for overnight treatment. The samples were then washed in distilled water, soaked in a $\mathrm{NaOH}$ solution $(150 \mathrm{~g} \mathrm{NaOH}$ in $1 \mathrm{~L}$ water) for $45 \mathrm{~min}$, neutralised with $\mathrm{HCl}$ solution (3\%) for $45 \mathrm{~min}$ in an ultrasonic bath, and washed in distilled water until a neutral $\mathrm{pH}$ was reached. Wood and cellulose extracts were dried at $50{ }^{\circ} \mathrm{C}$ and weighed into silver capsules $(\sim 1 \mathrm{mg})$, pyrolysed to $\mathrm{CO}$ at $1450{ }^{\circ} \mathrm{C}$ (PYRO-cube, Elementar, Langenselbold, Germany) and measured on a Delta Plus XP isotope ratio mass spectrometer (Thermo

Finnigan MAT, Bremen, Germany), which was linked to the pyrolysis unit by an open split ConFlo III interface (Thermo Finnigan MAT). Standard deviation (SD) of the mean for standard material was typically $<0.2 \%$. All $\delta^{18} \mathrm{O}$ values in this article are expressed in \%o using the "delta" notation: 
$\delta^{18} \mathrm{O}(\%)=\mathrm{R}_{\text {sample }} / \mathrm{R}_{\text {standard }}-1$

where $\mathrm{R}_{\text {sample and }} \mathrm{R}_{\text {standard }}$ are the ${ }^{18} \mathrm{O} /{ }^{16} \mathrm{O}$ ratio of the sample and the standard, respectively. All values are referenced to the VSMOW scale using international standards (benzoic acids 601 and 602, Vienna, Austria).

\section{Organic extraction from filter samples}

Filter pieces were transferred to teflon-coated centrifuge tubes and extracted four times in solvent mixtures of decreasing polarity: (1) Methanol (MeOH):dichloromethane (DCM) (2:1), (2) MeOH:DCM $(1: 2),(3,4)$ DCM. Each step included 15 seconds vortexing followed by 15 minutes ultrasonication. Supernatants from all steps were merged and transferred to pre-baked glass tip flasks and the solvent was evaporated to several $\mathrm{mL}$ by rotary evaporation (water bath temperature $35{ }^{\circ} \mathrm{C}$ ). Subsequently samples were transferred to $1.5 \mathrm{~mL}$ vials and divided in two for backup and further treatment.

\section{Organic extract sample derivatisation}

Total extracts were methylated according to a modified Purdie reaction, a derivatisation method that does not affect the compound $\delta^{18} \mathrm{O}$ value by additional oxygen ${ }^{[38]}$. The extracts in MeOH:DCM were evaporated to dryness and redissolved in $1 \mathrm{~mL}$ acetonitrile $(\mathrm{MeCN}) .65 \mathrm{mg} \operatorname{Ag}_{2} \mathrm{O}, 100 \mu \mathrm{L}$ methyl iodide (MeI, Sigma-Aldrich, Buchs, SG, Switzerland) and $20 \mu \mathrm{L}$ dimethyl sulfide (DMS, $\left(\mathrm{CH}_{3}\right)_{2} \mathrm{~S}$, Merck, Zug, Switzerland) were added. To aid mixing and prevent formation of a hard pellet during derivatisation, two small glass beads were added. The reaction mixture was shaken in the dark for 24 hours, after which the vials were spiked with $50 \mu \mathrm{L}$ MilliQ water, vortexed and centrifuged. The supernatant was then transferred to a new vial and concentrated as required for $\delta^{18} \mathrm{O}$ analysis. Specificity of the reaction and analytical method was checked with pure standards of levoglucosan on a GC-quadrupole mass spectrometer (Thermo Fisher Scientific ISQ, Bremen, Germany), and only one product was found, showing that all three free OH-groups were 
methylated.

$\mathrm{Ag}_{2} \mathrm{O}$ for derivatisation was freshly prepared from silver nitrate to ensure optimal basicity for derivatisation. $15 \mathrm{~g}$ silver nitrate $\left(\mathrm{AgNO}_{3}\right.$, Sigma-Aldrich) and $3.5 \mathrm{~g}$ sodium hydroxide $(\mathrm{NaOH}$, VWR, Dietikon, Switzerland) were dissolved separately in $100 \mathrm{~mL}$ MilliQ water $\left(80-90{ }^{\circ} \mathrm{C}\right)$ and then mixed. The resulting brown precipitate $\left(\mathrm{Ag}_{2} \mathrm{O}\right)$ was filtered under vacuum through a fritted glass filter (pore size of 40-100 $\mu \mathrm{m}$; Winzer, Wertheim, Germany) and washed with $100 \mathrm{~mL}$ MilliQ water and $100 \mathrm{~mL} \mathrm{99 \%} \mathrm{ethanol.} \mathrm{The} \mathrm{remaining} \mathrm{pellet} \mathrm{was} \mathrm{dried} \mathrm{at} 60{ }^{\circ} \mathrm{C}$ for $5 \mathrm{~h}$, ground to a fine powder with a pestle and mortar and stored in a desiccator filled with silica gel in a lightimpermeable vial, since $\mathrm{Ag}_{2} \mathrm{O}$ is sensitive to light.

Initially also derivatisations with bis(trimethylsilyl)trifluoracetamide (BSTFA) were carried out. These derivatisations, like the methylation reaction described above, also do not affect the $\delta^{18} \mathrm{O}$ value of the sample. However, the addition of silyl groups presents problems with the pyrolysis reactor and reactor lifetime was greatly reduced. Furthermore, methylated products have a lower mass and shorter retention time than trimethylsilyl derivatives, making them more amenable to IRMS analysis since with shorter GC retention times and consequently lower GC temperatures baseline interferences are less problematic. Finally, in case of planned ${ }^{13} \mathrm{C}$ and ${ }^{2} \mathrm{H}$ analyses, methylation adds fewer methyl groups than TMS-derivatisation does ( 1 vs. 3 per OH-group) to the molecule of interest, reducing the error in the calculation of the isotopic composition.

\section{Identification of compounds and oxygen isotope measurements}

Compound-specific stable oxygen isotope ratios were determined using GC/Pyr-IRMS (Trace GC Ultra, GC-IsoLink, and ConFlo IV coupled to a MAT253 isotope ratio mass spectrometer, all supplied by Thermo Fisher Scientific, Bremen, Germany). The split-splitless injector operated in splitless mode at $250{ }^{\circ} \mathrm{C}$. We placed glass wool and glass beads in the injector liner to prevent precipitation of non-product derivatisation residues on the column. Methylated total extracts were separated by gas chromatography over a $60 \mathrm{~m}, 0.25 \mathrm{~mm}$ inner diameter, $0.25 \mu \mathrm{m}$ film thickness 
Semi-Volatiles capillary column (Zebron, Phenomenex, Torrance, CA, USA). Carrier gas (He 5.0 and better) flow was $1.4 \mathrm{~mL} \min ^{-1}$ and the oven temperature programme consisted of $50{ }^{\circ} \mathrm{C}, 1 \mathrm{~min}$ isothermal, followed by $10{ }^{\circ} \mathrm{C} \min ^{-1}$ to $120{ }^{\circ} \mathrm{C}, 4{ }^{\circ} \mathrm{C} \min ^{-1}$ to $170{ }^{\circ} \mathrm{C}, 20{ }^{\circ} \mathrm{C} \min ^{-1}$ to $290{ }^{\circ} \mathrm{C}$ and finally $15.5 \mathrm{~min}$ isothermal (42 minutes total GC time). With this we achieved appropriate compound separation for isotope analysis of anhydrosugars. Peak retention time of methylated levoglucosan was observed after $1153 \mathrm{~s}$ in both standards and samples (Fig. S1). After GC separation the sample was pyrolysed to $\mathrm{CO}$ at $1280{ }^{\circ} \mathrm{C}$ in a $32 \mathrm{~cm}$ platinum tube partly filled with Ni wires (Thermo Fisher Scientific) and $\delta^{18} \mathrm{O}$ values determined from the ratio of $\mathrm{m} / \mathrm{z} 30$ to $\mathrm{m} / \mathrm{z} 28$. To ensure reducing conditions in the reactor, an auxiliary gas of $\mathrm{He} 6.0$ with $1 \% \mathrm{H}_{2} 6.0$ (Messer, Lenzburg, Switzerland) was added in continuous flow before the reactor ${ }^{[38]}$. Regular tests of IRMS instrument linearity and stability demonstrated no significant isotopic variations. Three $\mathrm{CO}$ reference gas pulse injections both before and after the analysis in backflush mode showed a isotopic variation of $\leq 0.1 \%$. The pyrolysis reactor was conditioned with one injection of $1 \mu \mathrm{L}$ toluene, followed by multiple blank injections (with backflush on during the solvent peak retention time window) until a stable baseline level was reached with the $m / z 30$ background stabilising between 130 and $200 \mathrm{mV}$. The backflush flow that is directed backwards through the reactor towards the gas chromatograph was only interrupted for $100 \mathrm{~s}$ to allow $\delta^{18} \mathrm{O}$ analysis of levoglucosan (Fig. S1). This reduces two separate potential negative effects on $\delta^{18} \mathrm{O}$ measurements: 1) $\mathrm{N}_{2} \mathrm{O}$ entering the ion source, which can lead to the formation of NO-ions, i.e. $m / z 30$, and 2) organic compounds other than levoglucosan entering the reactor and the isotope ratio mass spectrometer. The second issue was observed especially during the retention time window of polycyclic aromatic hydrocarbons present in the samples, which cannot be observed on $\mathrm{m} / \mathrm{z}$ traces 28, 29 and 30, but do cause a local rise in the GC baseline. In addition, we found that a liquid $\mathrm{N}_{2}$ trap after the pyrolysis reactor stabilises and improves the reproducibility of $\delta^{18} \mathrm{O}$ values. With this set-up instrument drift was eliminated. Each sample was measured in triplicate and corrected for sample amount effects when necessary. The correction was based on a linear fit through raw $\delta^{18} \mathrm{O}$ 
values from levoglucosan standards of different concentrations that were interspersed between the sample measurements. The difference between the raw $\delta^{18} \mathrm{O}$ values of the standards and the regression was determined and added to the raw $\delta^{18} \mathrm{O}$ values of the samples. Levoglucosan reference standard $\delta^{18} \mathrm{O}$ values were determined on a PYRO-cube elemental analyser (Elementar) coupled to an isotope ratio mass spectrometer (as described above) and referenced to the VSMOW scale.

\section{Results}

$\delta^{18} \mathrm{O}$ values of bulk wood, cellulose and levoglucosan in experimental and ambient samples

(1) Methylated levoglucosan could succesfully be measured in a concentration range of around 250 ng $\mu \mathrm{L}^{-1}$ to $2500 \mathrm{ng} \mu \mathrm{L}^{-1}$ by GC/Pyr-IRMS (Fig. S1), with a standard deviation (SD) of the mean that was better than $1.0 \%$ and an accuracy of $0.3 \%$. Levoglucosan concentrations below $250 \mathrm{ng} \mu \mathrm{L}^{-1}$ showed considerably stronger isotopic variations, representing the analytical detection limit.

(2) $\delta^{18} \mathrm{O}$ values of bulk wood in samples that were used for the wood burning experiments were 5.4 $\%$ (beech) and $6.1 \%$ (pine) lower than $\delta^{18} \mathrm{O}$ values of cellulose, reflecting the influence of ${ }^{18} \mathrm{O}-$ depleted lignin (Fig. 1A, Table 1). No significant difference in $\delta^{18} \mathrm{O}$ values between the tree species was found for bulk wood as well as cellulose. Furthermore, the wood was uniform in both species, with no significant difference in $\delta^{18} \mathrm{O}$ values between samples from various parts of the wood. $\delta^{18} \mathrm{O}$ values of cellulose were $30.0 \pm 0.6 \%$ for the beech wood from the northern side and $30.5 \pm 1.0 \%$ o for the pine wood from southern side of the Alps. $\delta^{18} \mathrm{O}$ values of levoglucosan from the wood burning experiments were $30.3 \pm 0.3 \%$ for beech and $30.7 \pm 1.4 \%$ for pine and thus not significantly different from $\delta^{18} \mathrm{O}$ values of cellulose. The cellulose-levoglucosan isotope fractionation within both species therefore was not more than $0.4 \%$ and within one standard deviation of the $\delta^{18} \mathrm{O}$ value of cellulose. 
(3) The $\delta^{18} \mathrm{O}$ value of levoglucosan that was treated with strongly ${ }^{18} \mathrm{O}$-depleted water vapour was $1.1 \%$ lower compared to the control. Since maximum natural isotopic variations in water vapour are about twentyfold lower compared to the experimental effect, a potential oxygen isotope exchange of levoglucosan with atmospheric humidity is negligible.

(4) $\delta^{18} \mathrm{O}$ values of levoglucosan in ambient samples from Magadino in southern Switzerland in 2011 were in the same range as those from the wood burning experiments, between $27.1 \%$ and $29.6 \%$, averaging around $28.4 \%$ (Fig. 1B, Table 2). $\delta^{18} \mathrm{O}$ values of levoglucosan in ambient samples from Preila in Lithuania were clearly lower than those from the other locations, indicating differences in source and/or processes during combustion.

\section{Discussion}

\section{Low cellulose-levoglucosan oxygen isotope fractionation during wood burning}

Two wood materials were chosen for the wood burning experiments, originating from two separate locations. In both bulk wood and cellulose, the oxygen isotopic composition of the two wood types was very similar (Fig. 1A, Table 1), with an ${ }^{18} \mathrm{O}$-enrichment of $5 \%$ and $6 \%$ in cellulose compared to bulk wood in beech and pine wood, respectively. This is similar to values reported by other studies ${ }^{[45,46]}$. The $\delta^{18} \mathrm{O}$ values of levoglucosan were not significantly different from the parent cellulose in both species. This is consistent with the small ${ }^{13} \mathrm{C}$ fractionation observed during biomass burning by other authors ${ }^{[1]}$ and suggests that at least under controlled burning conditions in an oven the source cellulose isotopic composition is largely retained in carbon and oxygen isotopes. In addition, the large isotopic difference between bulk wood and cellulose shows that cellulose extraction is important for studies comparing levoglucosan to potential source materials, as the analysis of bulk wood only could lead to an erroneous interpretation. Our results also indicate that the wood type (beech and pine in our study), and the accompanying difference in wood properties, has no influence on the oxygen isotope fractionation during wood burning. It is therefore possible to reconstruct the oxygen isotopic composition of the source cellulose from measurements 
of primary emissions of levoglucosan from controlled wood burning.

\section{Explanations for $\delta^{18} \mathrm{O}$ values of levoglucosan in ambient samples}

The aerosol samples from Magadino, southern Switzerland, were collected in winter, when local wood burning contributes significantly to the organic aerosol load in the area ${ }^{[41]}$. These samples yielded $\delta^{18} \mathrm{O}$ values of levoglucosan that were equal to or slightly lower than the primary emission samples of the wood burning experiments (Fig. 1B, Table 2). Based on the measured oxygen isotopic composition of levoglucosan between $27.1 \%$ and $29.6 \%$ and on the fact that we observed no isotope fractionation during controlled wood burning, it would thus follow that the source cellulose has a $\delta^{18} \mathrm{O}$ value of $27-30 \%$, which is an expected range for trees growing in these parts of Switzerland ${ }^{[47]}$.

The aerosol samples collected at the Preila site in Lithuania reflect a high loading event in March 2014. Here, rather low $\delta^{18} \mathrm{O}$ values were found. In contrast to the samples from Switzerland, the Lithuanian aerosols most likely did not have a local origin. 72-hour back trajectories, which model the atmospheric path of the air mass during the 3 days prior to its arrival at the sampling site, indicate that the air mass arriving at Preila had previously entrained emissions from large open grassland fires in the Kaliningrad region (Russia), Belarus and the Ukraine ${ }^{[44]}$. A dominance of levoglucosan in the organic extracts of these samples supports a biomass burning origin. A meteorological high pressure system over the study area caused stagnant conditions and extended the aerosol residence time, leading to particularly high concentrations.

Based on literature data we can infer the oxygen isotopic composition of precipitation water in the potential source regions of Russia and Belarus. Compared to Switzerland the $\delta^{18} \mathrm{O}$ value of precipitation water in the Belarussian source areas is expected to be around $2-3 \%$ lower ${ }^{[48]}$. If the same relationship between $\delta^{18} \mathrm{O}$ values of source water and cellulose holds for the biomass that was burned in the source area of this case study as for the trees from Switzerland (neglecting potential differences in leaf water isotopic enrichment due to transpiration), we would expect a $\delta^{18} \mathrm{O}$ value of 
cellulose, and by extension a $\delta^{18} \mathrm{O}$ value of levoglucosan, of around $24-27 \%$ (i.e. 2 - $3 \%$ lower than in Switzerland). However, the Lithuanian levoglucosan $\delta^{18} \mathrm{O}$ value was 1 to $4 \%$ lower than the expected range (20.1 and $23.3 \%$, Fig. 1B, Table 2). Two differences at the source of the aerosols, either the burned material (i.e. the grass vs. wood) or the fire conditions, may attribute to a lower $\delta^{18} \mathrm{O}$ value of levoglucosan in the aerosols and are discussed in the following:

1. The isotopic relationship between $\delta^{18} \mathrm{O}$ values of source water and carbohydrates such as cellulose is not necessarily the same for trees and for grasses ${ }^{[27]}$. While the biosynthetic fractionation factor $\left(\varepsilon_{O}\right)$ of tree-ring cellulose is often similar to the average $\varepsilon_{O}$ of $27 \%$ for plant compounds, the $\varepsilon_{O}$ of grass leaf cellulose can be much lower ${ }^{[27,49]}$. Helliker \& Ehleringer found in experiments under controlled conditions that $\varepsilon_{O}$ of grass leaf cellulose was dependent on relative humidity and that at low relative humidity $\left(37 \%\right.$, 24-h mean) $\varepsilon_{O}$ was below $20 \%{ }^{[49]}$. Even above $90 \%$ relative humidity the same authors found that $\varepsilon_{0}$ for cellulose was not higher than $25.5 \%$. This is most likely explained by the fact that cellulose is produced in less ${ }^{18} \mathrm{O}$-enriched leaf water pools in the intercalary meristem of the grass leaf base ${ }^{[27,49]}$. This less pronounced fractionation between leaf water and cellulose in grasses compared to trees results in lower grass cellulose $\delta^{18} \mathrm{O}$ values, and ultimately lower levoglucosan $\delta^{18} \mathrm{O}$ values. Thus, grass biomass burning in the Belarussian source area could partly explain why levoglucosan $\delta^{18} \mathrm{O}$ values in Lithuanian samples were considerably lower than expected for this source region (Fig. 1B, Table 2).

2. Whereas the wood burning experiments were conducted under controlled conditions with uniformly high temperatures in a closed oven, the grassland burning that was the potential source for the Lithuanian levoglucosan was probably more heterogeneous and contained more water. As a consequence, the average burning temperature was likely lower. Schumacher et al. ${ }^{[50]}$ found that $\delta^{18} \mathrm{O}$ values of $\mathrm{CO}_{2}$ evolving from biomass burning decreased with lowering of the combustion temperatures. High combustion temperatures may therefore suppress isotope fractionations, while lower temperatures may lead to higher isotope fractionations, consistent with theoretical expectations. Whether levoglucosan follows the same trend as $\mathrm{CO}_{2}$, or perhaps an inverse trend, is 
unclear, and must be the subject of future studies. In summary, temperature-dependent isotope fractionation processes might explain the lower $\delta^{18} \mathrm{O}$ values of levoglucosan in the Lithuanian ambient samples compared to those from other samples (Figs. 1A, 1B).

In addition, environmental conditions and chemical reactions during transport could theoretically influence $\delta^{18} \mathrm{O}$ values of levoglucosan in the air. In contrast to the controlled burning experiments and the Swiss ambient samples, the air mass that arrived at the Lithuanian field site was transported through the atmosphere for several days. We found that a potential oxygen exchange with atmospheric water vapour, which would change the $\delta^{18} \mathrm{O}$ values during transport, is likely not a factor. Additionally, photo-oxidation of levoglucosan might play a role during long-distance transport of aerosol samples ${ }^{[51,52]}$. However, it has been suggested that levoglucosan photooxidation proceeds through $\mathrm{H}$-abstraction from the carbon atoms, subsequently oxidising the oxygen in the hydroxyl functional group to a carbonyl group ${ }^{[53]}$. Since the O-atoms are not lost or exchanged, we expect that the influence of photo-oxidation is of minor importance here ${ }^{[53,54]}$.

Nevertheless, without samples of the original biomass that was burned, we cannot exclude the possibility that isotope fractionation took place during burning or transport, and it is important for future research that oxygen isotope studies on organic aerosols are done under controlled conditions. We conclude that the relatively low levoglucosan $\delta^{18} \mathrm{O}$ values found at the Lithuanian compared to the Swiss station are likely a combined result of the differences in vegetation and burning conditions.

\section{Conclusion}

Methylation of levoglucosan in aerosol extract mixtures yielded complete methylation of all free OH-groups, ensuring one product only, leading to precise and accurate $\delta^{18} \mathrm{O}$ measurements. The $\delta^{18} \mathrm{O}$ values of levoglucosan from the wood burning experiments were not significantly different from the values of cellulose, indicating no or very small oxygen isotope fractionation under the controlled conditions, independent of the species (beech or pine). This suggests that oxygen 
isotopes can be used as an ecological tracer of wood burning in the atmosphere.

This conclusion is supported by results of ambient samples from southern Switzerland, where aerosol levoglucosan $\delta^{18} \mathrm{O}$ values were consistent with local vegetation. Aerosol samples from Lithuania yielded lower levoglucosan isotope values than aerosol samples from Swiss wood burning, which is partially consistent with the history of the air mass, having traversed regions with active biomass (grass) burning in Belarus and the Ukraine. In that region the biomass is expected to be ${ }^{18} \mathrm{O}$-depleted compared to Switzerland due to differences in regional source water $\delta^{18} \mathrm{O}$ values. Furthermore, cellulose derived from grass-type vegetation rather than wood, as well as low burning temperatures may cause an additional ${ }^{18} \mathrm{O}$-depletion in levoglucosan. Thus, we show that on regional scales with a several per mil range in $\delta^{18} \mathrm{O}$ values of precipitation water and cellulose, the $\delta^{18} \mathrm{O}$ signal of the source water is ultimately transferred via biomass production and its burning to the levoglucosan in aerosols. $\delta^{18} \mathrm{O}$ values of levoglucusan are therefore a potential tool to determine and confine the location of the emission source, e.g. to trace atmospheric pollution from illegal crop burning back to its source region.

\section{Acknowledgments}

We thank Lola Schmid (PSI) and Manuela Oettli (WSL) for their laboratory support with cellulose extraction and elemental analyser measurements. Furthermore, we are grateful to Christoph Hüglin, who provided the samples from the Magadino station. This work was supported by the LithuanianSwiss Cooperation Programme "Research and Development" project AEROLIT (No. CH-3-ŠMM01/08). MS and MML acknowledge the financial support by the Swiss National Science Foundation (SNF, No. 200020_166162). RTWS acknowledges the financial support for the acquisition of the CSIA instrumentation by SNF (REQUIP, No. 206021_128761). 


\section{References}

[1] S. N. Pandis, N. M. Donahue, B. N. Murphy, I. Riipinen, C. Fountoukis, E. Karnezi, D. Patoulias, K. Skyllakou. Introductory lecture: Atmospheric organic aerosols: insights from the combination of measurements and chemical transport models. Faraday Discuss. 2013, $165,9-24$.

[2] J. L. Jimenez, M. R. Canagaratna, N. M. Donahue, A. S. H. Prevot, Q. Zhang, J. H. Kroll, P. F. DeCarlo, J. D. Allan, H. Coe, N. L. Ng, A. C. Aiken, K. S. Docherty, I. M. Ulbrich, A. P. Grieshop, et al. Evolution of organic aerosols in the atmosphere. Science 2009, 326, 1525 1529.

[3] C. Alves, A. Vicente, C. Pio, G. Kiss, A. Hoffer, S. Decesari, A. S. H. Prévôt, M. C. Minguillón, X. Querol, R. Hillamo, G. Spindler, E. Swietlicki. Organic compounds in aerosols from selected European sites - Biogenic versus anthropogenic sources. Atmos. Environ. 2012, 59, 243-255.

[4] B. L. van Drooge, M. Crusack, C. Reche, C. Mohr, A. Alastuey, X. Querol, A. S. H. Prévôt, D. a. Day, J. L. Jimenez, J. O. Grimalt. Molecular marker characterization of the organic composition of submicron aerosols from Mediterranean urban and rural environments under contrasting meteorological conditions. Atmos. Environ. 2012, 61, 482-489.

[5] D. C. Ballentine, S. a Macko, V. C. Turekian. Variability of stable carbon isotopic compositions in individual fatty acids from combustion of $\mathrm{C} 4$ and $\mathrm{C} 3$ plants : implications for biomass burning. Chem. Geol. 1998, 152, 151-161.

[6] S. Kato, H. Akimoto, M. Bräunlich, T. Röckmann, C. A. M. Brenninkmeijer. Measurements of stable carbon and oxygen isotopic compositions of $\mathrm{CO}$ in automobile exhausts and ambient air from semi-urban Mainz, Germany. Geochem. J. 1999, 33, 73-77.

[7] V. C. Turekian. Concentrations, isotopic compositions, and sources of size-resolved, particulate organic carbon and oxalate in near-surface marine air at Bermuda during spring. $J$. Geophys. Res. 2003, 108, D5. 
[8] S. G. Aggarwal, K. Kawamura. Molecular distributions and stable carbon isotopic compositions of dicarboxylic acids and related compounds in aerosols from Sapporo, Japan: Implications for photochemical aging during long-range atmospheric transport. J. Geophys. Res. 2008, 113, D14301.

[9] D. C. Ballentine, S. Macko, V. C. Turekian, W. P. Gilhooly, B. Martincigh. Compound specific isotope analysis of fatty acids and polycyclic aromatic hydrocarbons in aerosols: implications for biomass burning. Org. Geochem. 1996, 25, 97-104.

[10] R. Fisseha, M. Saurer, M. Jäggi, S. Szidat, R. T. W. Siegwolf, U. Baltensperger. Determination of stable carbon isotopes of organic acids and carbonaceous aerosols in the atmosphere. Rapid Commun. Mass Spectrom. 2006, 20, 2343-2347.

[11] X. F. Sang, I. Gensch, W. Laumer, B. Kammer, C. Y. Chan, G. Engling, A. Wahner, H. Wissel, A. Kiendler-Scharr. Stable carbon isotope ratio analysis of anhydrosugars in biomass burning aerosol particles from source samples. Environ. Sci. Technol. 2012, 46, 3312-3318.

[12] B. R. T. Simoneit. Compound-specific carbon isotope analyses of individual long-chain alkanes and alkanoic acids in Harmattan aerosols. Atmos. Environ. 1997, 31, 2225-2233.

[13] V. C. Turekian, S. Macko, D. Ballentine, R. J. Swap, M. Garstang. Causes of bulk carbon and nitrogen isotopic fractionations in the products of vegetation burns: laboratory studies. Chem. Geol. 1998, 152, 181-192.

[14] G. Schkolnik, Y. Rudich. Detection and quantification of levoglucosan in atmospheric aerosols: A review. Anal. Bioanal. Chem. 2006, 385, 26-33.

[15] B. R. T. Simoneit, J. J. Schauer, C. G. Nolte, D. R. Oros, V. O. Elias, M. P. Fraser, W. F. Rogge, G. R. Cass. Levoglucosan, a tracer for cellulose in biomass burning and atmospheric particles. Atmos. Environ. 1999, 33, 173-182.

[16] R. Fisseha, M. Saurer, M. Jäggi, R. T. W. Siegwolf, J. Dommen, S. Szidat, V. Samburova, U. Baltensperger. Determination of primary and secondary sources of organic acids and carbonaceous aerosols using stable carbon isotopes. Atmos. Environ. 2009, 43, 431-437. 
[17] G. D. Farquhar, J. R. Ehleringer, K. T. Hubick. Carbon Isotope Discrimination and Photosynthesis. Annu. Rev. Plant Physiol. Plant Mol. Biol. 1989, 40, 503-537.

[18] W. Dansgaard. Stable isotopes in precipitation. Tellus XVI 1964, 4, 436-468.

[19] G. Dongmann, H. W. Nürnberg, H. Förstel, K. Wagener. On the enrichment of $\mathrm{H}_{2}{ }^{18} \mathrm{O}$ in the leaves of transpiring plants. Radiat. Environ. Biophys. 1974, 11, 41-52.

[20] G. D. Farquhar, J. Lloyd, Carbon and oxygen isotope effects in the exchange of carbon dioxide between plants and the atmosphere, in Perspectives of Plant Carbon and Water Relations from Stable Isotopes, (Eds: A.E. Hall, I. Ting, J. Eheleringer, G.D. Farquhar). Academic Press, 1993, pp. 47-70.

[21] M. Saurer, A. V. Kirdyanov, A. S. Prokushkin, K. T. Rinne, R. T. W. Siegwolf. The impact of an inverse climate-isotope relationship in soil water on the oxygen-isotope composition of Larix gmelinii in Siberia. New Phytol. 2016, 209, 955-964.

[22] K. Treydte, D. Frank, J. Esper, L. Andreu, Z. Bednarz, F. Berninger, T. Boettger, C. M. D’Alessandro, N. Etien, M. Filot, M. Grabner, M. T. Guillemin, E. Gutierrez, M. Haupt, et al. Signal strength and climate calibration of a European tree-ring isotope network. Geophys. Res. Lett. 2007, 34, L24302.

[23] G. J. Bowen. Isoscapes: spatial pattern in isotopic biogeochemistry. Annu. Rev. Earth Planet. Sci. 2010, 38, 161-187.

[24] A. Kahmen, D. Sachse, S. K. Arndt, K. P. Tu, H. Farrington, P. M. Vitousek, T. E. Dawson. Cellulose $\delta^{18} \mathrm{O}$ is an index of leaf-to-air vapor pressure difference (VPD) in tropical plants. Proc. Natl. Acad. Sci. U. S. A. 2011, 108, 1981-1986.

[25] J. Uchikawa, R. E. Zeebe. The effect of carbonic anhydrase on the kinetics and equilibrium of the oxygen isotope exchange in the $\mathrm{CO}_{2}-\mathrm{H}_{2} \mathrm{O}$ system: Implications for $\delta^{18} \mathrm{O}$ vital effects in biogenic carbonates. Geochim. Cosmochim. Acta 2012, 95, 15-34.

[26] L. Sternberg, M. J. DeNiro. Biogeochemical implications of the isotopic equilibrium fractionation factor between the oxygen atoms of acetone and water. Geochim. Cosmochim. 
Acta 1983, 47, 2271-2274.

[27] M. M. Lehmann, B. Gamarra, A. Kahmen, R. T. W. Siegwolf, M. Saurer. Oxygen isotope fractionations across individual leaf carbohydrates in grass and tree species. Plant. Cell Environ. 2017, 40, 1658-1670.

[28] M. J. DeNiro, S. Epstein. Isotopic composition of cellulose from aquatic organisms. Geochim. Cosmochim. Acta 1981, 45, 1885-1894.

[29] D. Yakir, M. J. Deniro. Oxygen and hydrogen isotope fractionation during cellulose metabolism in Lemna gibba L. Plant Physiol. 1990, 93, 325-332.

[30] S. L. Voelker, J. R. Brooks, F. C. Meinzer, J. Roden, A. Pazdur, S. Pawelczyk, P. Hartsough, K. Snyder, L. Plavcová, J. Šantruček. Reconstructing relative humidity from plant $\delta^{18} \mathrm{O}$ and $\delta \mathrm{D}$ as deuterium deviations from the global meteoric water line. Ecol. Appl. 2014, 24, 960975.

[31] K. Treydte, S. Boda, E. Graf Pannatier, P. Fonti, D. Frank, B. Ullrich, M. Saurer, R. Siegwolf, G. Battipaglia, W. Werner, A. Gessler. Seasonal transfer of oxygen isotopes from precipitation and soil to the tree ring: Source water versus needle water enrichment. New Phytol. 2014, 202, 772-783.

[32] J. S. Roden, G. Lin, J. R. Ehleringer. A mechanistic model for interpretation of hydrogen and oxygen isotope ratios in tree-ring cellulose. Geochim. Cosmochim. Acta 2000, 64, 21-35.

[33] N. Patris, S. S. Cliff, P. K. Quinn, M. Kasem, M. H. Thiemens. Isotopic analysis of aerosol sulfate and nitrate during ITCT-2k2: Determination of different formation pathways as a function of particle size. J. Geophys. Res. 2007, 112, D23301.

[34] M. B. Young, K. McLaughlin, C. Kendall, W. Stringfellow, M. Rollog, K. Elsbury, E. Donald, A. Paytan. Characterizing the oxygen isotopic composition of phosphate sources to aquatic ecosystems. Environ. Sci. Technol. 2009, 43, 5190-5196.

[35] Y. Scheidegger, M. Saurer, M. Bahn, R. Siegwolf. Linking stable oxygen and carbon isotopes with stomatal conductance and photosynthetic capacity: a conceptual model. 
Oecologia 2000, 125, 350-357.

[36] A. Gessler, J. P. Ferrio, R. Hommel, K. Treydte, R. A. Werner, R. K. Monson. Stable isotopes in tree rings: Towards a mechanistic understanding of isotope fractionation and mixing processes from the leaves to the wood. Tree Physiol. 2014, 34, 796-818.

[37] M. Greule, C. Hänsel, U. Bauermann, A. Mosandl. Feed additives: authenticity assessment using multicomponent-/multielement-isotope ratio mass spectrometry. Eur. Food Res. Technol. 2007, 227, 767-776.

[38] M. M. Lehmann, M. Fischer, J. Blees, M. Zech, R. T. W. Siegwolf, M. Saurer. A novel methylation derivatization method for $\delta^{18} \mathrm{O}$ analysis of individual carbohydrates by gas chromatography/pyrolysis - isotope ratio mass spectrometry. Rapid Commun. Mass Spectrom. 2016, 30, 1-8.

[39] M. M. Lehmann, G. R. Goldsmith, L. Schmid, A. Gessler, M. Saurer, R. T. W. Siegwolf. The effect of ${ }^{18} \mathrm{O}$-labelled water vapour on the oxygen isotope ratio of water and assimilates in plants at high humidity. New Phytol. 2017, 10.1111/nph.14788.

[40] M. F. Heringa, P. F. DeCarlo, R. Chirico, T. Tritscher, J. Dommen, E. Weingartner, R. Richter, G. Wehrle, A. S. H. Prévôt, U. Baltensperger. Investigations of primary and secondary particulate matter of different wood combustion appliances with a high-resolution time-of-flight aerosol mass spectrometer. Atmos. Chem. Phys. 2011, 11, 5945-5957.

[41] H. Herich, C. Hueglin, B. Buchmann. A 2.5 year's source apportionment study of black carbon from wood burning and fossil fuel combustion at urban and rural sites in Switzerland. Atmos. Meas. Tech. 2011, 4, 1409-1420.

[42] H. Herich, M. F. D. Gianini, C. Piot, G. Močnik, J. L. Jaffrezo, J. L. Besombes, A. S. H. Prévôt, C. Hueglin. Overview of the impact of wood burning emissions on carbonaceous aerosols and PM in large parts of the alpine region. Atmos. Environ. 2014, 89, 64-75.

[43] V. Ulevicius, S. Byčenkienè, V. Remeikis, A. Garbaras, S. Kecorius, J. Andriejauskienė, D. Jasinevičienè, G. Mocnik. Characterization of pollution events in the East Baltic region 
affected by regional biomass fire emissions. Atmos. Res. 2010, 98, 190-200.

[44] V. Ulevicius, Bycenkiené, C. Bozzetti, A. Vlachou, K. Plauškaité, G. Mordas, V. Dudoitis, G. Abbaszade, V. Remeikis, A. Garbaras, A. Masalaite, J. Blees, R. Fröhlich, K. R. Dällenbach, et al. Fossil and non-fossil source contributions to atmospheric carbonaceous aerosols during extreme spring grassland fires in Eastern Europe. Atmos. Chem. Phys. 2016, 16, 5513-5529.

[45] R. B. Weigt, S. Bräunlich, L. Zimmermann, M. Saurer, T. E. E. Grams, H. P. Dietrich, R. T. W. Siegwolf, P. S. Nikolova. Comparison of $\delta^{18} \mathrm{O}$ and $\delta^{13} \mathrm{C}$ values between tree-ring whole wood and cellulose in five species growing under two different site conditions. Rapid Commun. Mass Spectrom. 2015, 29, 2233-2244.

[46] O. V. Sidorova, R. T. W. Siegwolf, M. Saurer, M. M. Naurzbaev, E. a. Vaganov. Isotopic composition $\left(\delta^{13} \mathrm{C}, \delta^{18} \mathrm{O}\right)$ in wood and cellulose of Siberian larch trees for early Medieval and recent periods. J. Geophys. Res. Biogeosciences 2008, 113, 1-13.

[47] C. E. Reynolds-Henne, R. T. W. Siegwolf, K. S. Treydte, J. Esper, S. Henne, M. Saurer. Temporal stability of climate-isotope relationships in tree rings of oak and pine (Ticino, Switzerland). Global Biogeochem. Cycles 2007, 21, 1-12.

[48] P. M. Langebroek, M. Werner, G. Lohmann. Climate information imprinted in oxygenisotopic composition of precipitation in Europe. Earth Planet. Sci. Lett. 2011, 311, 144-154.

[49] B. R. Helliker, J. R. Ehleringer. Differential ${ }^{18} \mathrm{O}$ enrichment of leaf cellulose in $\mathrm{C} 3$ versus $\mathrm{C} 4$ grasses. Funct. Plant Biol. 2002, 29, 435-442.

[50] M. Schumacher, R. A. Werner, H. A. J. Meijer, H. G. Jansen, W. A. Brand, H. Geilmann, R. E. M. Neubert. Oxygen isotopic signature of $\mathrm{CO}_{2}$ from combustion processes. Atmos. Chem. Phys. 2011, 11, 1473-1490.

[51] S. H. Kessler, J. D. Smith, D. L. Che, D. R. Worsnop, K. R. Wilson, J. H. Kroll. Chemical sinks of organic aerosol: Kinetics and products of the heterogeneous oxidation of erythritol and levoglucosan. Environ. Sci. Technol. 2010, 44, 7005-7010.

[52] C. J. Hennigan, M. A. Miracolo, G. J. Engelhart, A. A. May, A. A. Presto, T. Lee, A. P. 
Sullivan, G. R. McMeeking, H. Coe, C. E. Wold, W. M. Hao, J. B. Gilman, W. C. Kuster, J. De Gouw, et al. Chemical and physical transformations of organic aerosol from the photooxidation of open biomass burning emissions in an environmental chamber. Atmos. Chem. Phys. 2011, 11, 7669-7686.

[53] R. Zhao, E. L. Mungall, A. K. Y. Lee, D. Aljawhary, J. P. D. Abbatt. Aqueous-phase photooxidation of levoglucosan - a mechanistic study using aerosol time-of-flight chemical ionization mass spectrometry (Aerosol ToF-CIMS). Atmos. Chem. Phys. 2014, 14, 96959705.

[54] X. F. Sang, I. Gensch, B. Kammer, A. Khan, E. Kleist, W. Laumer, P. Schlag, S. H. Schmitt, J. Wildt, R. Zhao, E. L. Mungall, J. P. D. Abbatt, A. Kiendler-Scharr. Chemical stability of levoglucosan: An isotopic perspective. Geophys. Res. Lett. 2016, 43, 5419-5424. 


\section{Tables}

Table 1: $\delta^{18} \mathrm{O}$ values in experimental samples from controlled wood burning experiments. Mean values and standard deviations of bulk wood, cellulose and levoglucosan of Swiss beech and pine samples are given $(n=2-8)$.

\begin{tabular}{ccc}
\hline Compound & Beech & Pine \\
& $\delta^{18} \mathrm{O}(\% \mathrm{o}) \pm 1 \mathrm{SD}$ & $\delta^{18} \mathrm{O}(\% \mathrm{\%}) \pm 1 \mathrm{SD}$ \\
\hline Bulk wood & $24.6 \pm 0.5$ & $24.4 \pm 0.8$ \\
Cellulose & $30.0 \pm 0.6$ & $30.5 \pm 1.0$ \\
Levoglucosan & $30.3 \pm 0.3$ & $30.7 \pm 1.4$ \\
\hline
\end{tabular}


Table 2: $\delta^{18} \mathrm{O}$ values of levoglucosan in ambient aerosol samples obtained from Magadino, Switzerland (CH, 2011) and from Preila, Lithuania (LTU, 2014). Mean values and standard deviations of triplicate measurements are given for each sample.

\section{Magadino $(\mathrm{CH})$}

Date $\quad \delta^{18} \mathrm{O}(\%) \pm 1 \mathrm{SD}$

\begin{tabular}{cc}
\hline $2011-01-25$ & $29.4 \pm 0.3$ \\
$2011-02-12$ & $29.6 \pm 0.5$ \\
$2011-02-14$ & $28.5 \pm 0.1$ \\
$2011-02-15$ & $27.1 \pm 0.6$ \\
$2011-03-12$ & \\
Date & Preila (LTU) \\
\hline $2014-03-09$ & $20.1 \pm 0.7$ \\
$2014-03-10$ & $23.3 \pm 0.4$ \\
\hline
\end{tabular}


Figure captions

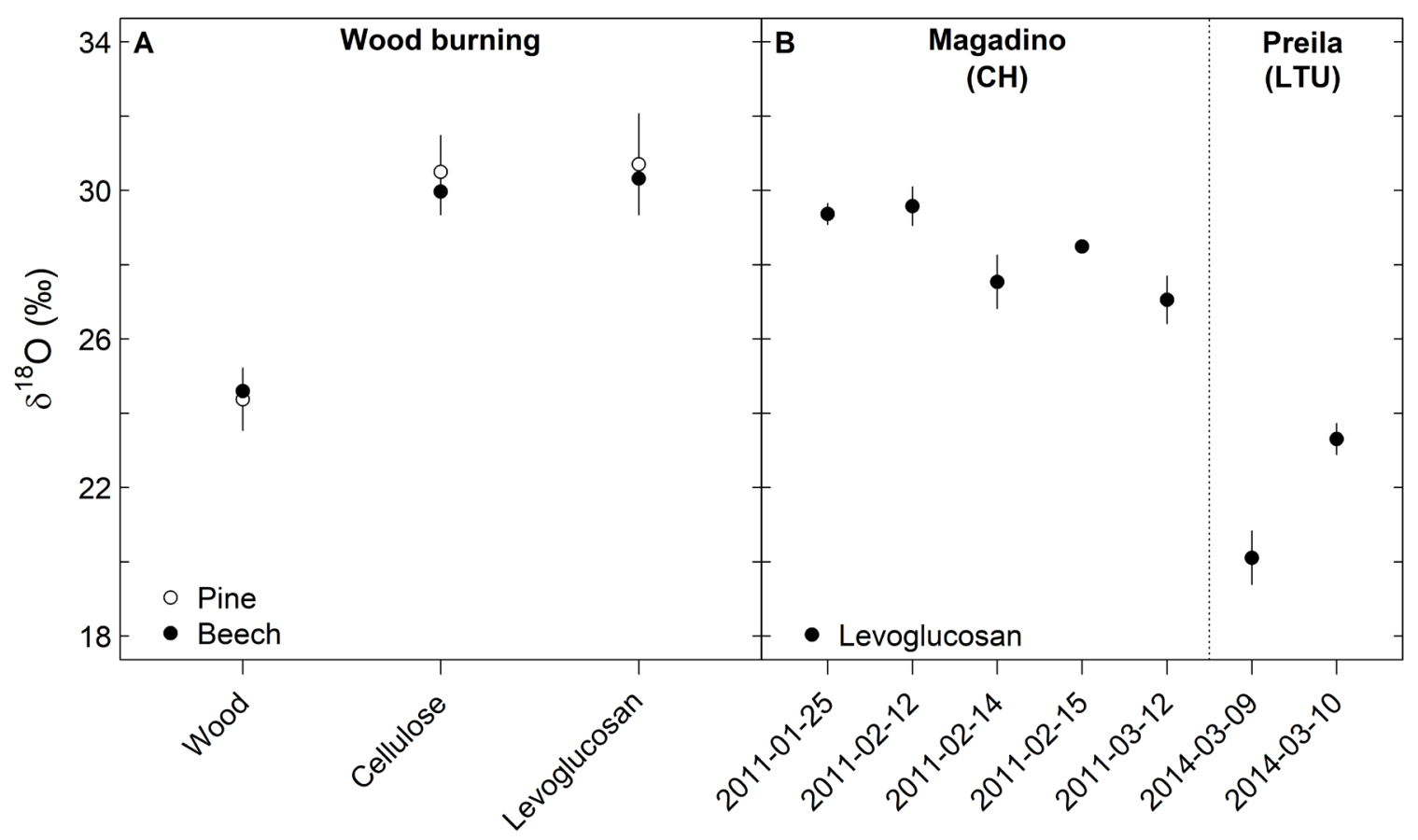

Fig. 1: A) $\delta^{18} \mathrm{O}$ values of bulk wood, cellulose and levoglucosan in experimental pine (open circle) and beech (closed circle) samples from controlled wood burning experiments $(\mathrm{n}=2-8)$. Mean values and standard deviations are given. B) $\delta^{18} \mathrm{O}$ values of levoglucosan in ambient aerosol samples obtained from Magadino, Switzerland (CH, 2011) and from Preila, Lithuania (LTU, 2014). Mean values and standard deviations of triplicate measurements are given for each sample. 